\title{
Response to the letter by Dr. Sharma
}

\section{(DOI 10.1007/s00415-009-5045-2)}

\author{
Martin A. Ritter - R. Dittrich • N. Thoenissen • \\ E. B. Ringelstein · D. G. Nabavi
}

Received: 25 September 2008/Accepted: 29 September 2008/Published online: 4 March 2009

(c) Springer-Verlag 2009

We thank Dr. Sharma for his important input. Dr. Sharma is correct in claiming that MES-detection looks only at one side of the picture of stenotic or atherosclerotic artery disease, namely the embolic potential. He is also correct in claiming that testing of the cerebro-vascular reserve capacity, even with tests as easy to perform as the breath-holding index, evaluates the hemodynamic component of stenosis much better. Furthermore, he is correct when he claims that a poor reserve capacity is of significance for the prediction of future stroke risk [1]. However, in our opinion, cerebro-vascular reserve capacity testing does not have the same importance as MESdetection, and there are even more difficulties in assessing the risk of patients who have a poor reserve capacity and MES.

First, it has been proven by MRI that ischemic strokes attributable to carotid stenosis are embolic and not hemodynamic in the vast majority of cases. Drawing from the more than 5,000 patients listed in the German stroke data bank, Grau showed that among patients with significant macroangiopathy, $90 \%$ had territorial and only $10 \%$ had hemodynamic infarctions [2]. Furthermore, hemodynamic compromise is not as frequent as one might think, even in high grade stenosis, due to the collaterals, which are usually effective in the circle of Willis. Furthermore, the cerebrovascualar reserve capacity has the tendency to improve with time [3], which also sheds doubt on the prognostic significance of future events. Therefore, the association of exhausted reserve capacity between future stroke risk is quite convincing from the studies published but much less convincing from pathophysiological considerations. The

M. A. Ritter $(\bowtie) \cdot$ R. Dittrich · N. Thoenissen ·

E. B. Ringelstein · D. G. Nabavi

Department of Neurology, University of Münster, Albert-Schweitzer-Str. 33, 48129 Munster, Germany

e-mail: ritterm@uni-muenster.de majority of patients are endangered by the embolic potential of stenosis and not by the hemodynamic compromise.

Furthermore, the tests used to assess reserve capacity are quite heterogeneous, even more heterogeneous than the methods to detect MES. For our review on the prospective risk of MES in arterial sources of embolism [4], we encountered a number of methodological variations in the studies that limited study comparability and made it quite hard to attribute a quantitative prospective risk. As Dr. Sharma writes, this is probably why the method is not overall accepted as a screening tool and the reason why we set up the review as published. With odds ratios $>5$ for both, symptomatic and asymptomatic carotid stenosis and acceptable confidence intervals we think we brought MESdetection a step closer to clinical routine use. We feel that a similar approach for the quantification of the additional stroke risk of an impaired cerebro-vascular reserve capacity is currently not possible due to a lack of data.

\section{References}

1. Silvestrini M, Silvestrini M, Vernieri F, Pasqualetti P, Matteis M, Passarelli F, Troisi E, Caltagirone C (2000) Impaired cerebral vasoreactivity and risk of stroke in patients with asymptomatic carotid artery stenosis. JAMA 283:2122-2127

2. Grau AJ, Weimar C, Buggle F, Heinrich A, Goertler M, Neumaier S, Glahn J, Brandt T, Hacke W, Diener HC (2001) Risk factors, outcome, and treatment in subtypes of ischemic stroke: the German stroke data bank. Stroke 32(11):2559-2566

3. Widder B, Kleiser B, Krapf H (1994) Course of cerebrovascular reactivity in patients with carotid artery occlusions. Stroke 25:1963-1967

4. Ritter MA, Dittrich R, Thoenissen N, Ringelstein EB, Nabavi DG (2008) Prevalence and prognostic impact of microembolic signals in arterial sources of embolism: a systematic review of the literature. J Neurol 255:953-961 